A Revista Summa Sapientiae é a publicação oficial da Faculdade Interna cional Cidade Viva e refleteo compromisso desta instituição na disseminação de um debate a cadêmico a tualizado e de alta qualidade na área das Ciências Humanas. A Revista enfa tiza temas de Teologia e de áreas afins.

\title{
Editor-Chefe
}

Dr. André Ricardo Fonsêca da Silva Faculdade Internacional Cidade Viva, Brasil

\section{Editores Adjuntos}

Ms. Thiago de Medeiros Dutra, Faculdade Internacional Cidade Viva, Brasil

\section{Conselho Editorial}

Dr. Iraquitan de Oliveira Caminha, Universidade Federal da Paraíba, Brasil

Dr. Sérgio Augusto de Queiroz, Faculdade Internacional Cidade Viva, Brasil

Dr. Cleverton Rodrigues Fernandes, Faculdade Internacional Cidade Viva, Brasil

Dra. Maria Marconiete Fernandes, Centro Universitário de João Pessoa, Brasil

Dra. Josevânia da Silva, Universidade Estadual da Paraíba, Brasil

Dr. Edward Jown Stetzer, Billy Graham Center, EUA

Dr. Craig Ott, Trinity Evangelical Divinity School, EUA

Ms. Guilherme de Carvalho, L'Abri Fellowship Brasil, Brasil

Ms. Franklin Ferreira, Seminário Martin Bucer, Brasil

Ms. Jonas Madureira, Faculdade Teológica Batista de São Paulo, Brasil

Ms. Josemar Jeremias Bandeira de Souza, Universidade Federal da Paraíba, Brasil

Ms. Fabiana Josefa do Nascimento Sousa, Faculdade Internacional Cidade Viva, Brasil

\section{Presidente Sistema Cidade Viva}

Sérgio Augusto de Queiroz

\section{Diretor - Fundação Cidade Viva \\ James Grisi}

Diretor - Faculdade Cidade Viva

Thiago de Medeiros Dutra

\section{Projeto Gráfico}

Ewerton Henrique Patrício

\section{Dados Internacionais de Catalogação na Publicação (CIP) \\ Biblioteca da FICV}

Revista Summa Sapientiae. / Faculdade Internacional Cidade Viva, Curso de Teologia. - V. 1, n. 1 (nov. 2018). João Pessoa: FICV, 2018.

Semestral.

1. Teologia - Periódico. 2. Cosmovisão cristã. I. Faculdade Internacional Cidade Viva - FICV. CDU 27-1: 316.75

Ficha catalográfica elaborada por Tirza Egito Rocha de Souza CRB - 15/ 0607

\section{Índices para catálogos sistemáticos:}

1. Teologia Cristã

2. Aspectos da cultura: Cosmovisão 